\title{
Mobile technologies in healthcare: systematising the move from point solutions to broad strategies
}

\author{
Payal Agarwal, ${ }^{1}$ Onil Bhattacharyya ${ }^{1,2}$
}

\begin{abstract}
'Institute for Health Systems Solutions and Virtual Care, and Women's College Research Institute, Women's College Hospital, University of Toronto, Toronto, Ontario M5G 1N8, Canada

${ }^{2}$ Frigon Blau Chair in Family Medicine Research and Department of Family and Community Medicine, University of Toronto, Toronto, Ontario, Canada
\end{abstract}

\section{Correspondence to}

Dr Onil Bhattacharyya, Institute for Health Systems Solutions and Virtual Care, and Women's College Research Institute, Women's College Hospital, University of Toronto, Toronto, ON M5G 1N8, Canada; onil.bhattacharyya@wchospital. ca

Received 15 June 2018 Revised 4 September 2018 Accepted 5 September 2018 Published Online First 29 September 2018

\section{Sinked}

- http://dx.doi.org/10.1136/ bmjqs-2018-007837

\section{Check for updates}

(C) Author(s) (or their employer(s)) 2018. No commercial re-use. See rights and permissions. Published by BMJ.

To cite: Agarwal $P$, Bhattacharyya O. BMJ Qual Saf 2018;27:865-867.
The presence of powerful computers in the pockets of most patients should transform how we practise medicine. Yet changes in practice to date have remained modest and occurred only gradually. ${ }^{1}$ Applications of new technologies often only emerge once the underlying technologies have become ubiquitous and long passed the period of counting as new. As one writer put it: 'Communication tools don't get socially interesting until they get technologically boring.'2 Once a technology reaches the stage of being taken for granted, it becomes easier to harness it for new functions and activities.

Cellphones with short message service (SMS) or text messaging first appeared 25 years ago, ${ }^{3}$ and by 2010 , users were sending 6.1 trillion texts per year globally. ${ }^{4}$ This tool had obvious applications for communication between physicians or to advise about critical lab results, where information could be displayed directly rather necessitating a return call on a pager. ${ }^{5}$ However, privacy concerns have limited texting of personal health information among healthcare providers. ${ }^{6}$ But there remains enormous potential benefit from this technology to engage with patients outside of clinic visits, since they all use text routinely.

In BMJ Quality \& Safety, Hirshberg et al describe the use of cellphone text messages to address postpartum hypertension (HTN). ${ }^{7}$ Squeezing clinic visits into busy lives is difficult for many patients, but mothers with newborn children clearly face particular challenges in this regard. While this randomised trial provides convincing evidence of the effectiveness of texting in this population, one wonders why it has taken so long to generate this use case, and how to realise the benefits of this approach in other clinical areas faster.
The trial compared the impact of text versus in-person visits to monitor postpartum HTN on the proportion of patients recording a single blood pressure (BP) in the first 10 days post partum. It also measured impact on prescription of new medications, office visits, emergency department (ED) visits and patient satisfaction. The trial recruited 206 patients and found significantly higher rates of patients recording one BP measure in the text group compared with control $(92.2 \%$ vs $43.7 \%)$. It found no difference in antihypertensive medication initiation or additional in-office or ED visits, but a higher proportion of patients attending their postpartum visit, and a lower rate of readmission in the text arm.

One strength of this study lies in its use of a range of measures to elucidate a potential mechanism of action. Patients in the text group recorded and submitted more BP values, so clinicians could more quickly adjust medications if needed. Patients in the text group did not send in other questions, so the effect entirely reflects reporting BPs rather than any other ancillary interactions between patients and clinicians. Patients in the text group did not feel that monitoring BP was more important than patients in the control group, so the increase in reporting was not due to a change in attitude, but more likely due to increased convenience. Patients in the text group felt that face-to-face communication was less important compared with patients in the control group, suggesting that exposure to text messaging with providers made them feel that it is a valuable way to interact. All patients in the text group would recommend this modality to friends or family, so satisfaction was high. Though medication initiation rates did not differ between both groups, timely 
reporting and earlier initiation of medications likely reduced $\mathrm{BP}$ and prevented hospital admissions in the intervention group. Consistent with this explanation, admission to hospital occurred for three out of four patients in the control group after documenting high $\mathrm{BP}$ at their office visit compared with zero patients in the intervention group.

This trial provides strong evidence due to its randomised design with balance of potential confounders across groups, high uptake of the intervention and low drop-out rates for major outcomes. This robust implementation likely reflects the multiple cycles of improvement, including testing of a range of features and mechanisms over 4 months that preceded this trial. ${ }^{8}$ In addition to this preparatory work, this study recruited patients over a 7-month period to establish its effectiveness. Self-monitoring and text message-based follow-up of chronic (or even acute) conditions is likely to be broadly applicable. Now that we have evidence in this group, how would a health system go on to 'discover' other potential target groups? And how can this be integrated into services more broadly?

Relatively good evidence shows the ability of text to support improvements in medication adherence, appointment attendance and attitude towards treatment and outcomes in most studies. ${ }^{9}$ The next step to maximise its impact would be to systematically expand its use to the most relevant problems and populations, given the minimal incremental cost of this intervention. One often encounters the characterisation of a technology as a 'solution looking for a problem' as a criticism. Yet, healthcare suffers so much from underuse of available solutions that inventing new ones for every problem seems profoundly wasteful. The critique of those peddling technological solutions is that they interfere with workflow. That criticism applies to some efforts to replicate information technology applications from other industries in healthcare. In this case, however, the technology solution is already deeply embedded in patient's lives. Moreover, the type of text messaging intervention used by Hirshberg and colleagues did not involve workflows of healthcare providers at all. Thus, 'solution looking for a problem' hardly applies to text messaging. It has already solved many problems in users' lives, so it seems perfectly appropriate to look for healthcare applications of this now ubiquitous technology.

Value proposition design is a method for 'discovering' other potential uses of a solution like text messaging, where it is rapidly tested in a range of target groups, to understand potential users, relevant features and possible benefits. ${ }^{10}$ Start-up companies developed this method when working under conditions of extreme uncertainty-for example, with a product that may not work, with no current customers who use it to learn from, and no business model to know if it can be sustained or scaled up. Value proposition design allows one to learn quickly, efficiently eliminating options unlikely to work, saving more rigorous testing for the stage where fit between the product or service and a public need becomes more apparent.

As shown in figure 1, the process starts from understanding the 'jobs to be done' by various groups (such

Value Proposition Design

A method developed to facilitate the creation of new products and services by managing the risk of failure using customer insights and rapid testing to identify potential problem-solution fits in 3 steps.

Method Description

Develop an understanding of the innovation using a visual canvas to outline:

1. Customer Profile: end user needs including "jobs to be done", current difficulties and desired benefits.

2. Value Canvas: opportunities for value creation by the innovation.

3. Fit: existing evidence to suggest the innovation addresses an important need for end users.

Prototype potential value propositions by quickly creating

inexpensive models to learn about the proposed "fit". Principles of

effective prototyping include:

1. Start with low fidelity prototypes that model key concepts

2. Create many versions and keep an open mind

3. Create contrasting models that spark conversations

Minimize uncertainty by testing ideas through small, quick experiments to focus efforts on highest value features.

1. Look for early signals of "fit" between product and users using "good enough" data

2. Quickly eliminate options that are unlikely to create value for end users

3. Conduct more rigorous testing once a clear fit between the product and end user is apparent
STEP 3: TEST

STEP 3. TEST

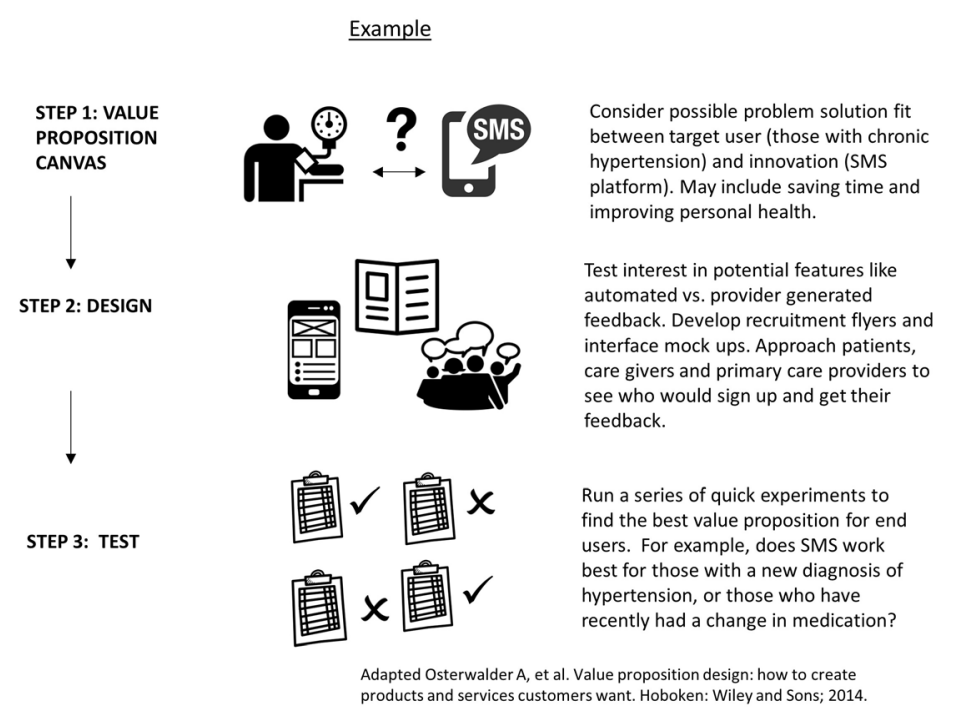

Adapted Osterwalder A, et al. Value proposition design: how to create
products and services customers want. Hoboken: Wiley and Sons; 2014

Figure 1 SMS, short message service. ${ }^{10}$ 
as patients, providers and payers), what difficulties they face and what benefits they are seeking. ${ }^{11}$ It also helps understand who derives value from this solution, as the value proposition for patients, providers and institutions is often quite different. For example, digital solutions that improve access and convenience for patients may increase workload for providers and liability for institutions. This step is followed by prototyping features that affect interest in using the service and testing use cases in different groups to find a good fit.

Drawing on the present study, one might ask why did the project work well for this population? Were there specific characteristics of the population (post partum) or disease (HTN) that made SMS the right technology? The next step is to find other problems this might be adapted for (eg, postpartum wound care) or populations (eg, general HTN management). Given the declining uncertainty around this approach and the possibility of a general mechanism of action, these evaluations should use small samples with short-term measures to identify groups highly likely to benefit and eliminating those who are unlikely to benefit. This approach provides answers that are 'roughly right' and help direct attention towards developing the right services rather than determining whether they work at this stage.

There are also a series of questions around the role of the technology platform. Did it have certain features that increased usage over traditional SMS or other platforms? What are the key features that need to be replicated for similar impact? They can be tested and eliminated in sequence as the project proceeds, to identify a series of target groups, clinical models, technology features and relevant outcomes. Once hypotheses around value have been validated for different populations, features and outcomes, the next issue is to understand how it scales. This intervention appears to be scalable because of its low cost, broad acceptability and relevance to multiple diseases, but it also rests on a central hub providing the feedback. In this study, the clinical service is based in obstetrics and gynaecology, but in a broader implementation, it could be provided through primary care, and involve various specialties as needed.

The rapid iteration in the pilot and the conduct of this randomised controlled trial were exemplary, but really this type of study should be embedded in most clinics' (or health system's) workflow. The bigger question is to understand what would be required for health systems to develop, iterate and formally test this type of intervention on a routine basis? This project was supported in part by the University of Pennsylvania's Center for Healthcare Innovation, which has a team of designers, developers and clinicians who are able to create, test and replicate approaches like this one across clinical areas. ${ }^{12}$ However, only a subset of health systems has dedicated innovation centres or teams that use digital tools to redesign health services. ${ }^{13}$ Making the most of 20 -year-old technology is already challenging. But, shortening the gap between what is technically possible and routinely done should be a core competency of health systems, rather than an esoteric research endeavour.

Funding The authors have not declared a specific grant for this research from any funding agency in the public, commercial or not-for-profit sectors.

Competing interests None declared.

Patient consent Not required.

Provenance and peer review Commissioned; internally peer reviewed.

\section{REFERENCES}

1 Rudin RS, Bates DW, MacRae C. Accelerating innovation in health IT. N Engl J Med 2016;375:815-7.

2 Shirky C. Here comes everybody: the power of organizing without organizations. New York: Penguin Books, 2008.

3 Gayomali C, 2012. The text message turns 20: A brief history of SMS. The Week. http://theweek.com/articles/469869/textmessage-turns-20-brief-history-sms [accessed 5 May 2018].

4 International Telecommunication Union (ITU), The World in 2010. http://www.itu.int/ITU-D/ict/material/FactsFigures2010. pdf [Accessed 6 Jul 2018].

5 Wu R. Turning the page on hospital communications slowly. BMJ Qual Saf 2017;26:4-6.

6 Storck L. Policy statement: texting in health care. J Nurs Info 2017;21.

7 Hirshberg A, Downes K, Srinivas S. Comparing standard office-based follow-up with text-based remote monitoring in the management of postpartum hypertension: a randomised clinical trial. BMJ Qual Saf 2018;27:871-7.

8 Hirshberg A, Vandertuyn M, Mahraj K. Rapid-cycle innovation testing of text-based monitoring for management of postpartum hypertension. J Clin Outcomes Manag 2017;24:77-85.

9 Kannisto KA, Koivunen MH, Välimäki MA. Use of mobile phone text message reminders in health care services: a narrative literature review. J Med Internet Res 2014;16:e222.

10 Osterwalder A, Pigneur Y, Bernarda G. Value proposition design: how to create products and services customers want. Hoboken: Wiley and Sons, 2014.

11 Christensen CM, Hall T, Dillon K. Know your customers' jobs to be done. Harvard Business Review 2016.

12 Hostetter M, Klein S, McCarthy D, 2015. Enabling change in health care. https://medium.com/@CommonwealthFund/pennmedicine-center-for-health-care-innovation-enabling-change612703a8f53b [accessed 4 Apr 2018].

13 Hostetter M, Klein S, McCarthy D, 2015. Findings from a survey of health care delivery innovation centres. http://www. commonwealthfund.org/publications/chartbooks/2015/apr/ survey-of-health-care-delivery-innovation-centers 